Radioprotection, vol. 46, $\mathrm{n}^{\circ} 6$ (2011) S745-S750

(C) EDP Sciences, 2011

DOI: $10.1051 /$ radiopro/20116875s

\title{
Radioecology and Society: A mutual need
}

\author{
C. Tamponnet \\ Institut de Radioprotection et de Sûreté Nucléaire- Scientific Direction, CE Cadarache \\ Bldg 229, P.O. Box 3, 13115 Saint Paul lez Durance, France
}

\begin{abstract}
Radioecology is defined as the study of the behaviour and effects of ionising radiations and radionuclides in the environment. Until recently, ecosystems were only considered in radioecology as an intermediate compartment between the source of radiation and man.

Interest in the effects of ionising radiation and radionuclides on the environment has recently increased because of the surge in the public awareness concerning the different sources of pollution of the environment and their effects on human health, the evolution of paradigm by the ICRP concerning the radiation protection of the environment, and the increase in our knowledge in that specific field of research.

Radioecology is now a mature scientific domain which is standing on its own feet. Its maturity can be assessed in different domains: (i) Education: with the appearance and development of masters in Radioecology worldwide, it is becoming a proper teaching domain in Higher Education; (ii) networks of excellence: international collaboration are initiated all over the world; (iii) Regulation: radiation protection of the environment is becoming a major point of concern along with the radiation protection of the public worldwide (ICRP, IAEA, IUR,... ) and more specifically in the European Union; (iv) Public concern: the public mind is now open for and in an urgent need for more information about the implications of human activities, and among them those producing and releasing ionising radiations and radionuclides, on his own environment and health, i.e. on his personal feeling of well-being.
\end{abstract}

\section{INTRODUCTION}

Radioecology is a branch of ecology which addresses the problems of natural and man-made radioactivity in the environment in terms of transfer and effects on biota [1]. It is often opposed with radiobiology which is essentially concerned with effects on humans.

Since its first appearance in 1956, Radioecology and Society are strongly connected. Indeed, Society had practical questions pertaining to military and civilian nuclear activities such as:

- the risks of environmental radioactive contamination from plutonium reactors (both in the USA and the USSR)

- the potential harmful effects of the global fall-out of man-made radionuclides by the large scale atmospheric tests of nuclear weapons,

- the potential consequences of a nuclear war such as the destruction of radiosensitive ecosystems,

- the impact of peaceful applications of nuclear energy, mainly electricity generation and nuclear excavations.

As a consequence, considerable funding was made available due to the importance of the problems at stake and Radioecology progressed rapidly in order to provide answers to these societal questions.

Therefore, in early years, ecosystems were only considered in radioecology as an intermediate compartment between the source of radiation and man (Fig. 1). In fact, research activities in radioecology focussed essentially on the studies of transfers of radionuclides in the ecosystems and not on their effects on biota.

This was an anthropocentric approach of radioecology, mainly imposed since the Second World War by Society, and reinforced in 1977 by the first recommendations of the International Commission on Radiological Protection on the radiation protection of the environment [2]: 


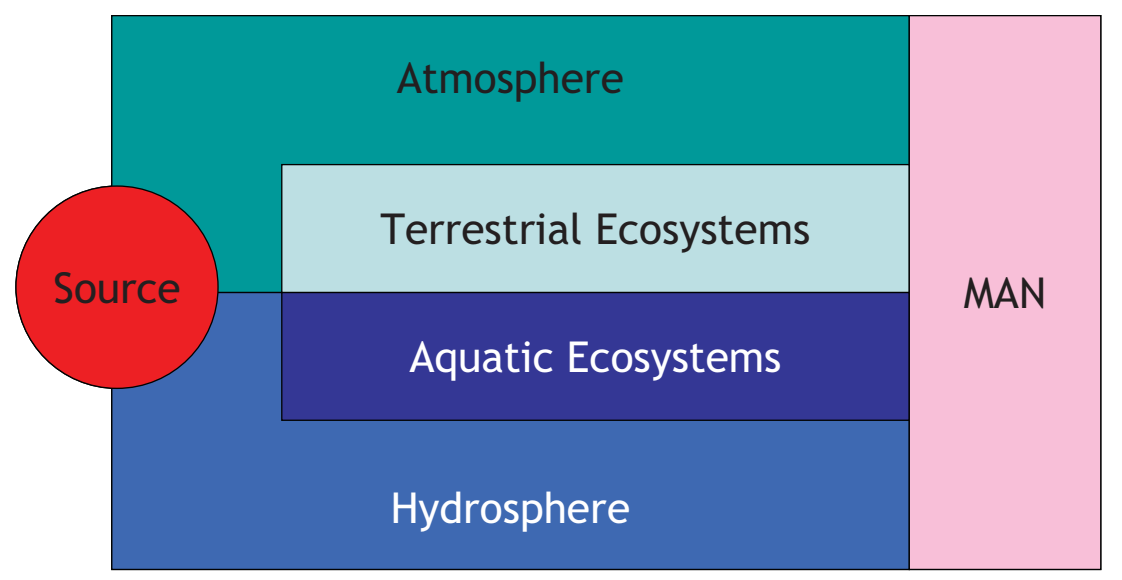

Figure 1. Ecosystems as an intermediate between the source of radionuclides and the main target: Man.

(\$14) Although the principal objective of radiation protection is the achievement and maintenance of appropriately safe conditions for activities involving human exposure, the level of safety required for the protection of all human individuals is thought likely to be adequate to protect other species, although not necessarily individual members of those species. The Commission therefore believes that if man is adequately protected then other living things are also likely to be sufficiently protected.

Such an approach was modified at the margin when the International Commission on Radiological Protection produced new recommendations in 1990 [3]:

(\$16) The Commission believes that the standard of environmental control needed to protect man to the degree currently thought desirable will ensure that other species are not put at risk. Occasionally, individual members of non-human species might be harmed, but not to the extent of endangering whole species or creating imbalance between species. At the present time, the Commission concerns itself with mankind's environment only with regard to the transfer of radionuclides through the environment, since this directly affects the radiological protection of man.

In more explicit terms, the system of protection of the International Commission on Radiological Protection provided protection for humans. Although ecological information may be incomplete, the full application of the system of protection was not thought to endanger whole species or to create imbalance between species. The International Commission on Radiological Protection had not dealt explicitly with radiological protection of the environment, although non-human organisms may well have been afforded an indirect measure of protection as a result of the controls on radionuclide concentrations in environmental media established as part of the system of radiological protection of humans.

Many, particularly from industry, contended that the environment was already sufficiently protected from radiation, and that there was no reason to put resources into the development of a system to protect non-human organisms.

\section{EVOLUTION IN PUBLIC AWARENESS}

The risk of a major nuclear disaster (nuclear war) progressively vanished following the signature of nuclear treaties between the two superpowers and completely disappeared with the end of the Soviet Union in the early nineties. This was accompanied by a profound decline in funding for radioecology.

But in the same period of time, two major accidents occurred (Three Miles Island and Chernobyl), the latter releasing huge amounts of radionuclides in the environment and contaminating large 
surfaces of soil in Europe (mainly in Ukraine, Russia and Belarus). These events had two conflicting consequences:

- A stagnation in the use of civilian nuclear energy,

- An increase in the funding in radioecology.

As we have now registered the $25^{\text {th }}$ anniversary of the Chernobyl accident, funding in radioecology again has largely diminished. Especially in Europe, funding from the European Commission (EURATOM) has so largely decreased that many laboratories involved in radioecological studies and researches have either disappeared or completely moved away from radioecology.

But, nearly at the same time, development of space activities introduced a huge evolution in the instrumentation of environmental sciences. Observation satellites allowed environmental scientists to have access to new sets of data and global effects of human activities were characterized:

- Appearance of polar holes in atmospheric Ozone Layer,

- Global increase in greenhouse effects gazes,

- Evidence of trace concentrations of pollutants in atmosphere and hydrosphere,

- ...

Therefore, Society got access to global information (for instance from the United Nations-sponsored International Panel on Climate Change) on potential adverse effects of human activities and along with that public awareness surged, asking for more information and more regulation.

Indeed, Society's concern for environmental risks has put pressure on policy makers and regulators to define protection strategies that specifically and explicitly include the environment, as evidenced by a growing number of international and national legal commitments. This reflected a need to protect the environment in order to maintain a suitable environment in which humans can exist, and a concern for the environment per se. In turn, these concerns reflect worries related to the possible effects of ionising radiation on the environment, as well as a desire to protect the environment from a wide range of harmful influences. To meet the broader concerns, strategies for protection of the environment were increasingly required to be applicable to radiation as well as other pollutants.

\section{RADIOECOLOGY: A CHANGE OF PARADIGM}

Such an approach from Society enhanced contributions from the radioecological community [4-6] towards more environmentally oriented recommendations concerning radioecology goals including the development of the scientific basis for protection of the environment from radiation to fill some crucial knowledge gaps. During the same period of time, the International Commission on Radiological Protection adopted the conclusions of a task group set up three years ago to advise on the development of a policy for the protection of the environment and to suggest a framework based on scientific and ethical principles [7].

The proposed framework was designed to harmonise with the International Commission on Radiological Protection approach to the protection of human beings, but did not intend to set regulatory standards. Instead, the framework was intended to be a practical tool to provide high-level advice and guidance for regulators and operators. An agreed set of quantities and units, a set of reference dose models, reference dose-per-unit-intake (or unit exposure), and reference fauna and flora were required to serve as a basis for the more fundamental understanding and interpretation of the relationships between exposure and dose and between dose and certain categories of effect, for a few, clearly defined types of animals and plants. As a first step, a small set of reference fauna and flora with supporting databases were to be developed by the International Commission on Radiological Protection. Others can then develop more area- and situation-specific approaches to assess and manage risks to non-human species.

Such a change of paradigm in radioecology was reinforced in the Chapter 8 of the Publication 103 of the International Commission on Radiological Protection in 2007 [8]. The revised recommendations acknowledge the importance of protecting the environment. The International Commission on Radiological Protection has previously concerned itself with mankind's environment only with regard to 


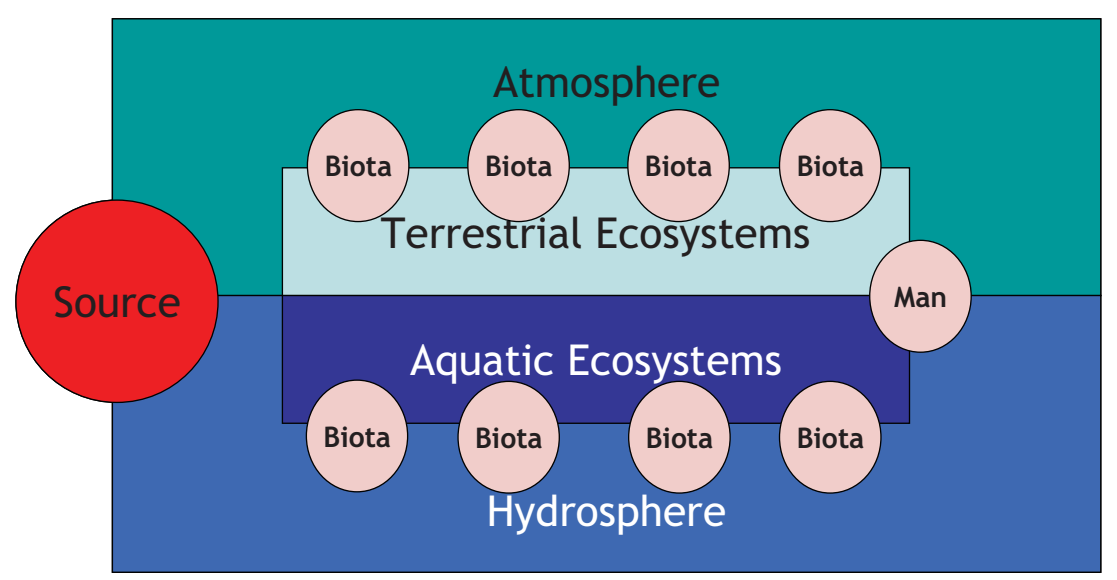

Figure 2. Holistic, biota oriented approach of the radiation protection of ecosystems.

the transfer of radionuclides through it, mainly in the context of planned exposure situations. In such situations, the Commission continues to believe that the standards of environmental control needed to protect the general public would ensure that other species are not placed at risk. To provide a sound framework for environmental protection in all exposure situations, the use of Reference Animals and Plants is proposed. In order to establish a basis for acceptability, additional doses calculated to these reference organisms could be compared with doses known to have specific biological effects and with dose rates normally experienced in the natural environment. The International Commission on Radiological Protection, however, does not propose to set any form of 'dose limits' for environmental protection.

Finally, the International Commission on Radiological Protection introduced the concept of Reference Animals and Plants, defined a small set, and discussed their pathways of exposure [9]. It collated and discussed the adequacy of the best-available data relating to their dosimetry, at different stages of their life cycles, and further developed and used this information to derive sets of tabulated data that allow the dose to be calculated for 75 radionuclides that may be within, or external to, each organism.

It reviewed what was known about the effects of radiation upon such biotic types (or of organisms similar to them, where more precise data were lacking), and thus derived a set of consideration reference levels for each biotic type in order to help optimise the level of effort that might be expended on their environmental protection, or that of similar types of organisms. The various factors that should be taken into account when considering what to do if such derived consideration reference levels are attained or exceeded were also discussed.

Some broader background information on the types of animals and plants used was also given Additional information was provided regarding extrapolation and interpolation of the limited set of dosimetric models to other shapes and sizes of animals and plants.

Therefore, one should reminder that we are switching from an anthropocentric approach of radioecology towards an holistic, biota oriented approach in which man is only one biota, may be important and acting, among many others inside our biosphere.

\section{RADIOECOLOGY: A MATURE DOMAIN OF SCIENCE?}

As often in science, new domains appear because of the discovery of new phenomena: the discovery of radioactivity by Henri Becquerel and purification and studies of purified radionuclides by Pierre and Marie Curie induced the creation of new domains in physics (nuclear physics and engineering, ..) but also in biology (radiobiology) and ecology (radioecology). 
Table 1. Non-exhaustive list of educational programs in Radioecology.

\begin{tabular}{|l|c|c|}
\hline Title & Institution & Country \\
\hline $\begin{array}{l}\text { European Master of } \\
\text { Science in Radioecology }\end{array}$ & $\begin{array}{c}\text { Norwegian University of Life Sciences } \\
\text { Aix Marseille University, INSTN }\end{array}$ & $\begin{array}{c}\text { Norway } \\
\text { France }\end{array}$ \\
\hline $\begin{array}{l}\text { Master Degree in Radiochemistry } \\
\text { and Radioecology }\end{array}$ & $\begin{array}{c}\text { Saint Kliment Ohridski } \\
\text { Sofia University }\end{array}$ & Bulgaria \\
\hline $\begin{array}{l}\text { MSc in Health Physics / } \\
\text { Radioecology }\end{array}$ & Colorado State University & USA \\
\hline Master degree in Radioecology & Ukrainian Radiologic Center of Kiev & Ukraine \\
\hline $\begin{array}{l}\text { MSc in nuclear Engineering } \\
\text { including Radioecology) }\end{array}$ & Chalmers University of technology & Sweden \\
\hline $\begin{array}{l}\text { Degree in Radioecology } \\
\text { Module of Radioecology in the } \\
\text { Master in Biology of Organism and Ecology }\end{array}$ & $\begin{array}{c}\text { International Sakharov Environmental } \\
\text { University of Minsk }\end{array}$ & Belarus \\
\hline $\begin{array}{l}\text { Module of Radioecology in the } \\
\text { Master of Chemistry }\end{array}$ & University of Liège & Belgium \\
\hline
\end{tabular}

Radioecology, considered as a sub-domain of ecology, ecotoxicology, is now a mature domain since its creation in 1956. It is standing on its own feet. Its maturity can be assessed in different domains:

- Education

- Networks of excellence

- Regulation

- Public concern:

\subsection{Education}

Some domains of nuclear sciences have already met an academic audience exemplified by the existence of higher education diploma at the post-graduate level such as masters. Until recently, this was not the case for radioecology mainly because of needs in personnel with high knowledge in radioecology were not considered as big enough to initiate such curricula.

But recently, a stakeholder assessment, carried out under the EU-EURAC and EU-ENEN II projects, clearly showed that at the European level, there are a significant and constant need for post-graduates with skills in radioecology along with radiation dosimetry, environmental modelling, radiobiologists and bio-modellers. Most of those needs are from government organizations and nuclear industry. It was concluded from this study that a new degree program in radioecology would efficiently met some of those needs [10].

Such an approach was only noticed in other parts of the world. Therefore, a non-exhaustive survey of educational program in radioecology is proposed in the following table.

The existence of such a pool of post graduate students with a master in radioecology will also nurture $\mathrm{Ph}$. D. programs in radioecology in dedicated institutions.

\subsection{Networks of excellence in Radioecology}

Such a renewal is exemplified in Europe with the creation of STAR (Strategy for Allied Radioecology), a European Network of Excellence in the seventh framework program of the European Union whose role is to promote an integrated approach to radioecology research in Europe.

Moreover, radioecology experts at the U.S. Department of Energy's Savannah River National Laboratory recognized an immediate need to build a pool of radioecology expertise both here and 
abroad. To address this need, they worked with partners from universities across the U.S. and laboratories in France and the Ukraine to form the National Center for Radioecology (NCoRE), a network of excellence for environmental radiation risk reduction and remediation.

Under the auspice of the International Union of Radioecologists a new task group has been initiated whose role is to engage an activity survey of radioecology in Asia. Its final goal is to establish an efficient international network among Asian countries for information exchange, monitoring and researches, as well as for human resource development.

\subsection{Regulation}

Evolution of regulation usually follows the evolution of ideas and knowledge concerning human activities. Therefore, radiation protection of the environment is becoming a major point of concern along with the radiation protection of the public worldwide (ICRP, IAEA, IUR,...) as seen here above (§3) and is going to induce modification in regulation at international, regional and national levels.

\subsection{Public concern}

Evolution in public awareness makes it now impossible to ignore the public opinion when dealing with activities affecting the environment. Therefore, the public mind is now open for and in an urgent need for more information and actions about the implications of human activities, and among them those producing and releasing ionising radiations and radionuclides, on his own environment and health, i.e. on his personal feeling of well-being.

\section{CONCLUSION}

Indeed, Radioecology is now recognized as a specific domain of Science Radioecology which is standing on its own feet. Its maturity can be assessed in different domains: (i) Education: with the appearance and development of masters in Radioecology worldwide, it is becoming a proper teaching domain in Higher Education and with networks of excellence initiated all over the world research in radioecology is promoted and facilitated (ii) Regulation: radiation protection of the environment is becoming a major point of concern along with the radiation protection of the public worldwide (ICRP, IAEA, IUR,...) and more specifically in the European Union; (iii) Public concern: the public mind is now open for and in an urgent need for more information about the implications of human activities, and among them those producing and releasing ionising radiations and radionuclides, on his own environment and health, i.e. on his personal feeling of well-being.

\section{References}

[1] Van der Stricht E. and Kirchmann R. Radioecology: radioactivity and ecosystems (UIR-IUR, Oupeye, Belgium, 2001) pp.1-15.

[2] International Commission on Radiological Protection. Ann. ICRP 1 (1977) 3.

[3] International Commission on Radiological Protection. Ann. ICRP 21 (1991) 1-3.

[4] Bréchignac F. Sci Total Environ 307 (2003) 35-54.

[5] International Union of Radioecologists Board of Council J environ Radioact 70 (2003) 155-159.

[6] Copplestone D., Howard B.J., and Bréchignac F. 74 (2004) 31-41.

[7] International Commission on Radiological Protection. Ann. ICRP 33 (2003) 3.

[8] International Commission on Radiological Protection. Ann. ICRP 37 (2007) 133-136.

[9] International Commission on Radiological Protection. Ann. ICRP 38 (2008) 15-16.

[10] Skipperud L., Salbu B., Priest N., Garelick H., Tamponnet C., Abbott A. and Mitchell P. Nuclear Engineering and Design 241 (2011) 1013-1017. 